\title{
Is another public health crisis brewing beneath the COVID-19 pandemic?
}

\author{
Erin Hobin ${ }^{1}$ (D) $\cdot$ Brendan Smith ${ }^{1}$
}

Received: 8 April 2020 / Accepted: 3 June 2020 / Published online: 18 June 2020

(C) Crown 2020

\begin{abstract}
Evidence indicates associations between exposure to mass traumatic events and increased alcohol consumption and related harms following the crises. However, there is limited evidence available to inform alcohol policies during such events. In this commentary, we present the range of government actions to control public access to alcohol during the novel coronavirus disease 2019 pandemic in provinces and territories across Canada. Liquor retailers, including both private and government-run retailers, have been designated as essential services in all jurisdictions, operating under an evolving set of rules. From a public health perspective, keeping liquor retailers open during pandemic-related lockdown restrictions is a delicate decision which poses new risks and considerations about the best strategy for minimizing alcohol-related harms. We discuss the need to strike a balance between supplying public access to alcohol, particularly to those living with dependence, and unintentionally sending the message that alcohol is essential in our lives and encouraging consumption. Given the far-reaching effects of alcohol on health, social, psychological, economic, and work safety outcomes, we describe international guidance for minimizing alcohol-related harms and suggest that a nuanced and evidence-informed discussion about the considerations and impacts of alcohol control measures during a public health emergency should be undertaken.
\end{abstract}

\section{Résumé}

Des associations ont pu être établies entre l'exposition à des événements traumatisants d'envergure et une hausse subséquente de la consommation d'alcool et des méfaits connexes. Or, nous disposons de peu d'éléments de preuve aptes à orienter les politiques en matière d'alcool durant de tels événements. Ce commentaire présente l'éventail des mesures gouvernementales adoptées pour contrôler l'accès des membres du public à l'alcool durant la pandémie de maladie à coronavirus 2019 dans les provinces et les territoires canadiens. Qu'ils soient issus du secteur privé ou public, les détaillants d'alcool ont obtenu la désignation de services essentiels dans l'ensemble du pays et ont pu poursuivre leurs activités en respectant une série de règles changeantes. Du point de vue de la santé publique, le maintien en activité des détaillants d'alcool en période de restrictions imposées pour cause de confinement pandémique est une décision délicate soulevant de nouveaux risques et de nouvelles questions à propos de la meilleure stratégie à adopter pour minimiser les méfaits de l'alcool. Nous discutons de la nécessité de maintenir un équilibre entre le fait d'assurer l'accès des membres du public à l'alcool, surtout chez les personnes aux prises avec une dépendance, et celui d'en encourager par inadvertance la consommation en véhiculant le message selon lequel l'alcool est essentiel dans nos vies. Étant donné les vastes répercussions de l'alcool sur le plan social, psychologique et économique, sur la sécurité au travail et sur la santé, nous décrivons les conseils formulés à l'échelle internationale pour en minimiser les méfaits et évoquons la nécessité d'entreprendre une discussion nuancée et fondée sur des données probantes relativement aux effets des mesures de contrôle de l'alcool durant une crise sanitaire et aux questions connexes.

Erin Hobin

erin.hobin@oahpp.ca

1 Public Health Ontario, 300 - 480 University Ave, Toronto, Ontario M5V 1G2, Canada 
Keywords Alcohol $\cdot$ COVID-19 $\cdot$ Alcohol policy $\cdot$ Pandemic

Mots-clés Alcool $\cdot$ COVID-19 $\cdot$ politique en matière d'alcool $\cdot$ pandémie

Public access to alcohol has been a somewhat neglected yet important topic during the novel coronavirus 2019 disease (COVID-19) pandemic. Evidence consistently shows a positive relationship between exposure to mass traumatic events, such as a terrorist attack or natural disaster, and increased population-level alcohol consumption following the crises in the shorter term, and up to 1 to 2 years post-event for those with higher exposure levels (Cerda et al. 2011; Keyes et al. 2011). However, there is limited evidence available to guide governments' response to manage public access to alcohol during such events. Consequently, there has been a varied response on how to address alcohol use during the COVID19 pandemic internationally. Some countries and jurisdictions, such as South Africa, Thailand, and Nuuk, the capital of Greenland, have banned alcohol sales completely, while governments in North America and most of Europe have deemed liquor retailers as essential services which continue to operate. Given the far-reaching effects of alcohol on health, social, psychological, economic, and work safety outcomes, a nuanced and evidence-informed discussion about the considerations and impacts of regulatory measures controlling alcohol access during a public health emergency should be undertaken.

Across Canada, a range of policy responses has been implemented to control access to alcohol during the COVID-19 lockdown restrictions, as both the definition of essential services and the regulation of alcohol sales are governed at the provincial and territorial levels (Table 1). Starting mid-March 2020, all provinces and territories declared a state of emergency restricting authority to operate to essential services. Liquor retailers, including both private and government-owned retailers, are designated as essential in all provinces and territories, and are operating under evolving rules. Alcohol sales generate billions of dollars in revenue each year for both the private and public sectors in Canada (Statistics Canada 2019). Health experts and substance use disorder specialists generally agree that liquor retailers should remain open during the pandemic to support individuals living with alcohol dependence and acute alcohol withdrawal-approximately $3 \%$ of Canadians aged $15+$ met the criteria for alcohol abuse or dependence in 2012 (Pearson et al. 2013). For individuals with dependence issues, side effects of abrupt alcohol withdrawal can include tremors, insomnia, nausea, and death. Prince Edward Island (PEI) was the only province to initially deem liquor retail outlets a non-essential service and require stores to close during the emergency lockdown period, with plans to offer alternative sources of alcohol for those with dependence issues. However, due to intense pressure the ban was quickly lifted to provide access in select provincial retailers with reduced trading hours (Prince Edward Island Liquor Control Commission 2020). Customers making multiple product purchases in the liquor retailers are also asked to limit the total value to \$250 (Prince Edward Island Liquor Control Commission 2020). In Newfoundland, private retailers are open but government-operated liquor stores are closed to the public, alcohol must be pre-ordered online or by phone for pick-up at select retailers, and purchases are capped at $\$ 100$ per transaction (Newfoundland and Labrador Liquor Corporation 2020). Some governments have opted to extend the days and hours of operation for specified private alcohol retailers, such as grocery stores, to accommodate vulnerable individuals shopping outside of regular business hours (Canadian Television Network 2020). Several governments, including Ontario, quickly amended regulations to permit existing on-premise alcohol licensees to continue alcohol sales as part of food orders for takeout or delivery (Alcohol and Gaming Commission of Ontario 2020). There is no limit on the amount of liquor that may be sold for takeout or delivery, and this amendment is effective until December 31, 2020 (Alcohol and Gaming Commission of Ontario 2020). These new regulations were positioned as a strategy for supporting businesses during the public health crisis (Alcohol and Gaming Commission of Ontario 2020).

From a public health perspective, keeping off-premise liquor retailers open during pandemic-related lockdown restrictions is a delicate decision which, while mitigating some risks, adds others, and poses considerations and questions about the best strategy for minimizing alcohol-related harms. In Canada, alcohol is the most commonly consumed substance, with $78 \%$ of individuals aged $15+(23.3$ million) consuming at least one alcoholic drink in the past year (Government of Canada 2017). While the majority of Canadians usually consume alcohol in low-risk patterns, in 2018, $19 \%$ of individuals aged $12+$ (5.7 million) reported heavy drinking (4+ drinks on one occasion for women and 5+ for men) at least monthly (Statistics Canada 2018). Since the start of COVID-19 lockdown restrictions, jurisdictions in Canada are witnessing massive surges in alcohol sales, by as much as $40 \%$ in British Columbia government-run liquor retailers. Physical retailers report long line-ups and stockpiling, and online retailers are overwhelmed with orders. Anecdotal reports from the Canadian territories indicate increases in bootlegged alcohol and price gouging during the pandemic due to the threat of restrictions on alcohol access. Another consideration for dealing with busy retail 


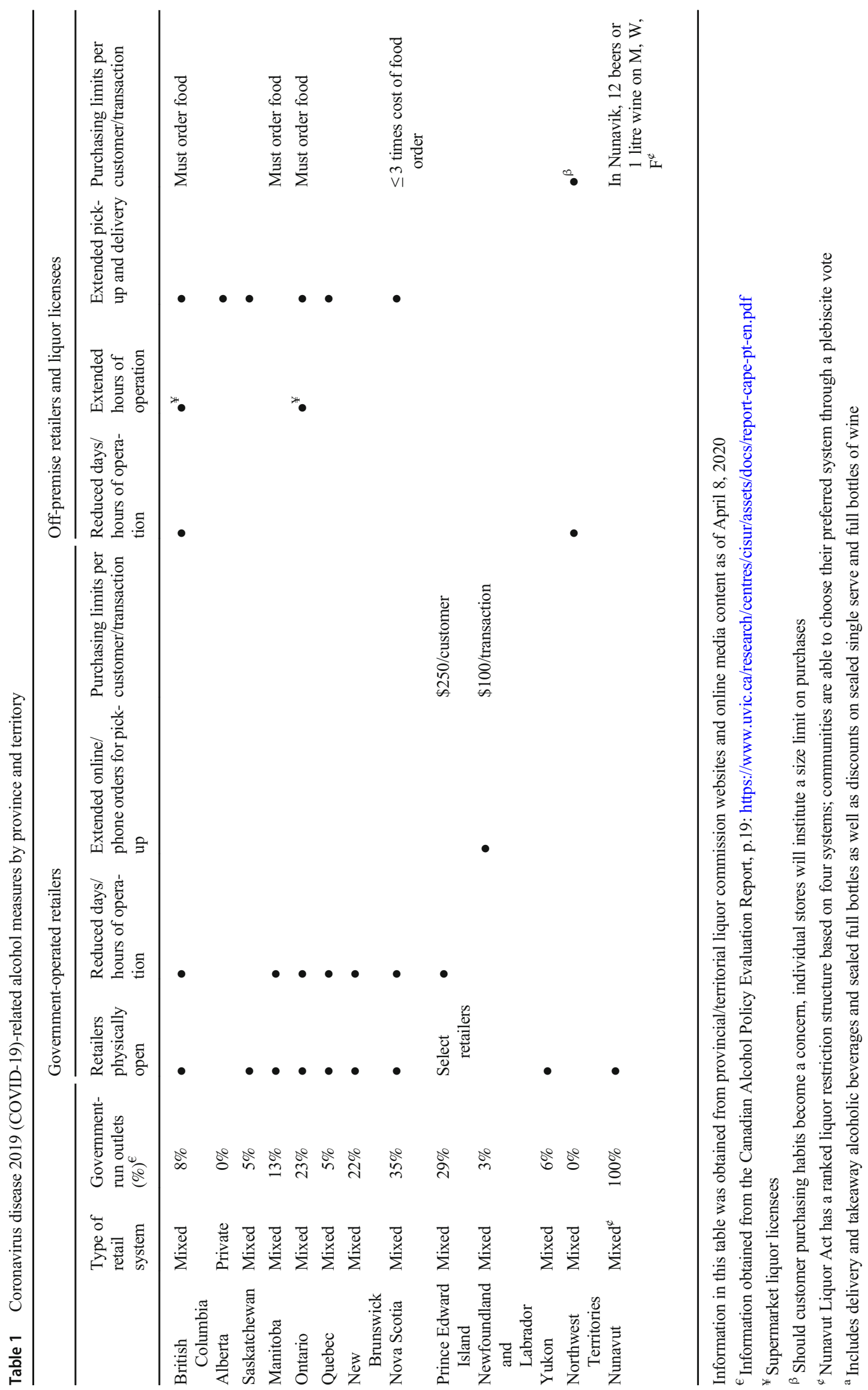


outlets is how best to manage retail employees' health and safety, as jurisdictions are now reporting that employees of government-run liquor retailers are infected with COVID19. Health and substance use experts acknowledge the challenge in striking a balance between supplying public access to alcohol, particularly for those dependent on alcohol to avoid withdrawal, and unintentionally sending the message that alcohol is essential in our lives and encouraging consumption.

Alcohol use is causally linked to more than 200 acute and chronic health conditions (Global Burden of Disease 2016 Alcohol Collaborators 2018). In Canada, rates of emergency department visits attributable to alcohol are increasing (Myran et al. 2019), and in 2015-2016, hospitalizations entirely caused by alcohol outnumbered heart attacks (Canadian Institute for Health Information 2017). Amid fears that the healthcare system could be overwhelmed by an influx of COVID-19 patients, the acute harms caused by alcohol for both the drinker and others, such as the risks of withdrawal, alcohol dependence, injury, and interpersonal violence, are particularly relevant. Chronic alcohol use disorder is already the top condition contributing to hospitalizations entirely attributable to alcohol in Canada (Canadian Institute for Health Information 2017), and international studies suggest as much as a $30 \%$ increase in this type of hospitalization following a mass traumatic event (Moise and Ruiz 2016). Moreover, heavy alcohol consumption is associated with increased susceptibility to respiratory infections, as well as acute respiratory distress syndrome, which could put additional strain on limited healthcare resources (Kershaw and Guidot 2008). The longer-term effects of the pandemic on alcohol use and related harms are another consideration, as evidence suggests outcomes could include further normalizing home drinking, reinforcing or introducing drinking as a way to self-medicate symptoms of stress, anxiety, and boredom, and increasing alcohol dependence (Cerda et al. 2011; Keyes et al. 2011; Moise and Ruiz 2016). Preliminary data suggest that similar trends may already be occurring in Canada, as a national survey found 19\% of Canadians aged 15-54 reported increases in their weekly alcohol consumption during the first phase of the COVID-19 pandemic (Statistics Canada 2020). The economic burden of alcohol use in Canada is already $\$ 14.6$ billion annually, exceeding that from all illicit substances combined and is similar to or, by some estimates, greater than tobacco (Canadian Substance Use Costs and Harms Scientific Working Group 2018).

The World Health Organization (WHO) has cautioned that alcohol is an unhelpful coping mechanism, and offered recommendations for limiting alcohol use during the pandemic (World Health Organization Regional Office for Europe 2020). Overall, the WHO advised to uphold existing regulations restricting access to alcohol during the COVID-19 pandemic (World Health Organization Regional Office for Europe 2020). Public health experts have also suggested implementing alcohol rationing, or capping transactions to control the quantity of alcohol being purchased, measures implemented in PEI and Newfoundland. This technique has been successfully applied to other consumer goods during the COVID-19 pandemic that pose no health risk to consumers, such as toilet paper in supermarkets. Governments, alcohol producers, and retailers have been asked to be vigilant about reminding the public of alcohol drinking guidelines and recommended limits on the quantity and frequency of consumption, and to consider implementing a public awareness campaign that encourages people to drink less, or at least not drink more than usual. This suggestion may be particularly important in Canada, as Canadian drinking culture is largely formed around changes in routine, such as on weekends, during job layoffs, and at other times we are off work (Paradis et al. 2009). Last, the WHO has acknowledged the importance of making vital substance use disorder services available during an emergency, and that mental health services should prepare for a surge in need as a result of the pandemic and physical distancing measures (World Health Organization Regional Office for Europe 2020).

Managing the psychological response to a mass traumatic event is one of the most critical factors in a society's ability to recover. Going forward, it is important to monitor alcohol sales and alcohol-attributable harms during and following the COVID-19 crisis. Understanding the range and pattern of these harms can aid in optimizing interventions and improving disaster preparedness and responses in the future. As an emergency evolves and the context rapidly changes, policymakers need clear evidence to inform decisions and actions. Further, it will be critical to track the status and evaluate the impact of the revised alcohol regulations after the COVID-19 restrictions end. While the measures were largely implemented to minimize physical contact and therefore COVID-19 transmission, some revisions have been made to support businesses by introducing new channels for the public to access alcohol. If these measures are not reversed postpandemic, they have the potential to increase populationlevel alcohol consumption and corresponding harms. The variations in policies controlling alcohol access across provinces and territories in Canada create an ideal environment to conduct natural experimental studies to compare different levels of public access to alcohol and alcohol-related outcomes during a mass public health emergency. Results from this work can advance knowledge of the implications of shifting the level of public access to alcohol in a crisis.

\section{Compliance with ethical standards}

Conflict of interest The authors declare that they have no conflict of interest. 


\section{References}

Alcohol and Gaming Commission of Ontario. Info bulletin no. 61: liquor sales licensees may now sell liquor for takeout or delivery along with food. March 26, 2020. https://www.agco.ca/blog/alcohol/mar2020/info-bulletin-no-61-liquor-sales-licensees-may-now-sellliquor-takeout-or. Accessed 7 Apr 2020.

Canadian Institute for Health Information. (2017). Alcohol harm in Canada: examining hospitalizations entirely caused by alcohol and strategies to reduce alcohol harm. Ottawa: CIHI https://www. cihi.ca/sites/default/files/document/report-alcohol-hospitalizationsen-web.pdf. Accessed 7 Apr 2020.

Canadian Substance Use Costs and Harms Scientific Working Group (2018). Canadian Institute for Substance Use Research; Canadian Centre on Substance Use and Addiction. Canadian substance use costs and harms (2007-2014). Ottawa: Canadian Centre on Substance Use and Addiction; 2018. http://www.ccsa.ca/ Resource\%20Library/CSUCH-Canadian-Substance-Use-CostsHarms-Report-2018-en.pdf. Accessed 7 Apr 2020.

Canadian Television Network. Alcohol can now be ordered with food take-out and delivery across Ontario. Sean Davidson. March 26, 2020. https://toronto.ctvnews.ca/mobile/alcohol-can-now-beordered-with-food-takeout-and-delivery-across-ontario-1.4869450? cache=almppngbro?clipId=68596. Accessed 7 April 2020 .

Cerda, M., Tracy, M., \& Galea, S. (2011). A prospective population based study of changes in alcohol use and binge drinking after a mass traumatic event. Drug Alcohol Depend, 115(1-2), 1-8.

Global Burden of Disease 2016 Alcohol Collaborators. (2018). Alcohol use and burden for 195 countries and territories, 1990-2016: a systematic analysis for the Global Burden of Disease Study 2016. Lancet, 392(10152), 1015-1035.

Government of Canada. Canadian Tobacco, Alcohol and Drugs Survey (CTADS): summary of results for 2017. https://www.canada.ca/en/ health-canada/services/canadian-tobacco-alcohol-drugs-survey/ 2017-summary.html\#n4. Accessed 20 May 2020.

Kershaw, C. D., \& Guidot, D. M. (2008). Alcoholic lung disease. Alcohol Research: Current Reviews, 31(1), 66-75.

Keyes, K., Hatzenbuehler, M., \& Hasin, D. (2011). Stressful life experiences, alcohol consumption, and alcohol use disorders: the epidemiologic evidence for four main types of stressors. Psychopharmacology (Berli), 218(1), 1-17.

Moise, I. K., \& Ruiz, M. O. (2016). Hospitalizations for substance abuse disorders before and after Hurricane Katrina: clustering and area- level predictors, New Orleans, 2004-2008. Preventing Chronic Disease. https://doi.org/10.5888/pcd13.160107.

Myran, D., Hsu, A., Smith, G., \& Tanuseputro, P. (2019). Rates of emergency department visits attributable to alcohol use in Ontario from 2003 to 2016: a retrospective population-level study. Can Med Assoc J. https://doi.org/10.1503/cmaj.181575.

Newfoundland and Labrador Liquor Corporation (2020) NLC's updated response to COVID-19. https://nlliquor.com/nlcs-updated-responseto-covid-19/. Accessed 7 Apr 2020.

Paradis, C., Demers, A., Picard, E., \& Graham, K. (2009). The importance of drinking frequency in elevating individuals' drinking patterns: implications for the development of national drinking guidelines. Addiction, 104, 1179-1184.

Pearson, C., Janz, T., Ali, J. (2013) Mental and substance use disorders in Canada. Health at a Glance. September. Statistics Canada. Catalogue no. 82-624-X. https://www150.statcan.gc.ca/n1/pub/82624-x/2013001/article/11855-eng.htm. Accessed 20 May 2020.

Prince Edward Island Liquor Control Commission. (2020) COVID-19 update. https://liquorpei.com/pei-liquor-covid-19-update/. Accessed 7 Apr 2020

Statistics Canada (2018) Net income of liquor authorities and government revenue from sale of alcoholic beverages (x 1,000). https:// www150.statcan.gc.ca/t1/tbl1/en/tv.action?pid=1010001201 . Accessed 7 Apr 2020.

Statistics Canada. Heavy drinking, 2018. Catalogue no.82-625-X. Health fact sheets, June 2019. https://www150.statcan.gc.ca/n1/en/pub/82625-x/2019001/article/00007-eng.pdf?st=YLmITBYm. Accessed 20 May 2020.

Statistics Canada.(2020) Canadians who report lower self-perceived mental health during the COVID-19 pandemic more likely to report increased use of cannabis, alcohol and tobacco. https://www150. statcan.gc.ca/n1/pub/45-28-0001/2020001/article/00008-eng.htm? $\mathrm{HPA}=1$. Accessed 20 May 2020.

World Health Organization Regional Office for Europe (2020) Alcohol does not protect against COVID-19; access should be restricted during lockdown. http://www.euro.who.int/en/health-topics/ disease-prevention/alcohol-use/news/news/2020/04/alcohol-doesnot-protect-against-covid-19-access-should-be-restricted-duringlockdown. Accessed 20 May 2020.

Publisher's note Springer Nature remains neutral with regard to jurisdictional claims in published maps and institutional affiliations. 